\title{
Variant Anatomy of Popliteal Vessels- A Cadaveric Study
}

\section{ABSTRACT}

Introduction: The popliteal fossa is a narrow intermuscular space posterior to knee joint. This area is vulnerable during knee arthroplasty or high tibial osteotomy. Therefore, awareness of anatomical variations in the popliteal fossa is important for anatomists, radiologists and surgeons. Popliteal Artery (PA) is frequently affected by penetrating and blunt trauma involving the lower extremity. Therefore, exposure of this artery is often required in both emergency and elective vascular procedures. The Popliteal Vein $(P V)$ is formed at the distal border of popliteus. Pulmonary embolisms originate in deep vein thrombosis in lower extremities. The thrombus forms in the calf veins and subsequently embolize to the lungs. With continued increase of interventional procedures, the anatomical variations in the region of popliteal fossa may have an influence on the success of surgical reconstruction, transluminal angioplasty or embolectomy.

Aim: To study the morphology and variations in popliteal vessels by dissection.
Materials and Methods: The present study was a cadaveric study which was conducted on 30 lower limbs belonging to 15 formalin fixed adult human cadavers. Properly embalmed adult human cadavers were included in the study. Cadavers with any lower limb deformity or with history of surgery in popliteal fossa were excluded from the study. The data was entered in Microsoft excel sheet and expressed in percentage.

Results: According to the classification given by Kim D et al., 96.6\% cases were classified as Type IA. Higher bifurcation of PA into posterior tibial and common trunk of anterior tibial and peroneal was described as Type IIB. In addition, the PV was seen to be formed at the lower border of popliteus in 28 specimens (93.33\%). Two specimens (6.67\%) showed a variable level of formation.

Conclusion: Considering such variable morphology of structures in the popliteal fossa, the surgeons operating around the knee joint should be aware of the possible variations in order to avoid undue complications.

Keywords: Deep vein thrombosis, High tibial osteotomy, Popliteal artery variations, Popliteal vein variations

\section{INTRODUCTION}

The popliteal fossa is a narrow intermuscular space posterior to knee joint. When the boundaries of the fossa are separated, its contents are revealed as the popliteal vessels, tibial nerve and its branches, common peroneal nerve and its branches, short saphenous vein, sural nerve, posterior femoral cutaneous nerve, articular branch from obturator nerve, lymph nodes and fat [1]. This area is vulnerable during knee arthroplasty or high tibial osteotomy [2]. Therefore, awareness of anatomical variations in the popliteal fossa is important for anatomists, radiologists and surgeons [3]. The PA is about $20 \mathrm{~cm}$ long. It begins at the hiatus in adductor magnus as continuation of femoral artery and ends at the lower border of popliteus muscle (greggor) where it divides into anterior and posterior tibial arteries [4]. It gives genicular branches, superior genicular arteries i.e., superior medial genicular artery (SMGA) and superior lateral genicular artery (SLGA), middle genicular artery (MGA), inferior genicular arteries i.e., inferior medial genicular artery (IMGA) and inferior lateral genicular artery (ILGA), muscular branches, cutaneous branches and sural arteries. The fixity of distal popliteal vessels at the lower angle of popliteal fossa results in frequent injury to these vessels when fractures and dislocations around knee joint occurs. The site of passage of this artery through adductor hiatus is a common area for atherosclerotic stenosis [5].

Morphological variations of PA has been reported to range from 4 to $14.6 \%$. A few classifications have been proposed for these morphological variants [6]. A currently used classification by Kim D et al., divides the branching pattern of PA into three types (I-III), with each type classified further into three subtypes (A-C).

\section{Type I (Normal division)}

IA: Normal pattern

IB: Trifurcation
IC: Anterior tibio- fibular trunk

Type II (High division)

IA: Anterior Tibial Artery (ATA) arises at or above popliteus muscle IIB: Posterior Tibial Artery (PTA) arises at or above popliteus muscle IIC: Fibular artery arises at or above popliteus muscle.

\section{Type III (Aplastic/Hypoplastic)}

IIIA: Hypoplastic/Aplastic PTA

IIIB: Hypoplastic/Aplastic ATA

IIIC: Hypoplastic/Aplastic PTA and ATA

Popliteal artery is a common receiving site for above and below knee bypass grafts. It is also frequently affected by penetrating and blunt trauma involving the lower extremity. Therefore, exposure of this artery is often required in both emergency and elective vascular procedures [7]. The PV is formed, at the distal border of popliteus, by the union of anterior and posterior tibial veins [6]. It ascends through the popliteal fossa to the opening in adductor magnus where it becomes femoral vein. Its tributaries are short saphenous vein, muscular vein and the veins corresponding to branches of PA. There are usually 4-5 valves in $\mathrm{PV}$ [1]

Pulmonary embolisms are thought to originate in deep vein thrombosis in lower extremities. The thrombus forms in the calf veins, propagate into femoro-popliteal system and subsequently embolize to the lungs [8]. The presence of numerous variations among deep vein within the popliteal fossa raises the risk of potential for deep vein thrombosis secondary to changes in flow velocities. This may also amplify the possibility of negative result during deep vein thrombosis diagnostic procedures in cases of a missed thrombus during ultrasonography image analysis [9]. 
The vascular system is known to display a wide range of anatomical variations. With continued increase of interventional procedures, the anatomical variations in this region may have an influence on the success of surgical reconstruction, transluminal angioplasty or embolectomy [10]. Thus, the present study was done with an aim to study the morphology and variations in popliteal vessels.

\section{MATERIALS AND METHODS}

The present study was a cadaveric study, conducted on 30 lower limbs belonging to 15 formalin fixed adult human cadavers which were dissected using Cunningham's Manual for Dissection Volume 1 [4]. The study was conducted over a period of 25 months (September 2012-October 2014). Properly embalmed adult human cadavers were included in the study. Cadavers with any lower limb deformity or with history of surgery in popliteal fossa were excluded from the study. Study was conducted after obtaining approval from the Institutional Ethical Committee (Ref. CMC/3505).

\section{STATISTICAL ANALYSIS}

The data was entered in Microsoft excel sheet and expressed in count (percentage).

\section{RESULTS}

PA, its branching pattern and level of termination was studied. Following observations were made in the genicular branches of PA:

a. In one limb (3.33\%), the IMGA originated at the level of femoral condyles. The remaining $96.67 \%$ showed a typical pattern for IMGA.

b. The ILGA originated at the level of femoral condyles in two specimens (6.67\%).

c. In all 30 limbs the MGA was given off in the center of fossa. However, the MGA was seen to be arising from a common trunk with SMGA and with SLGA in two cases.

d. Double MGA was seen in one specimen.

According to the classification given by Kim D et al., 96.7\% cases were classified as Type IA. Higher bifurcation of PA into posterior tibial and common trunk of anterior tibial and peroneal as Type IIB was seen in 1 case (3.3\%), Type II A was also seen in the same case [Table/Fig-1].

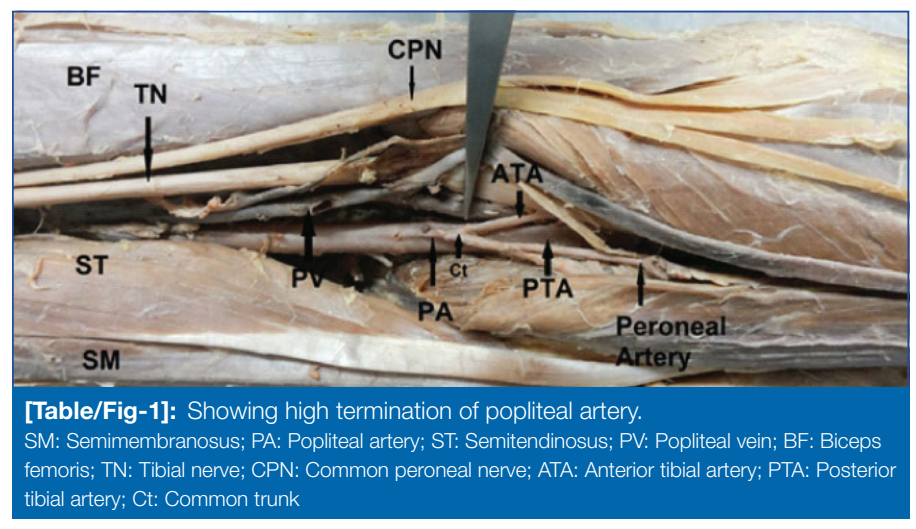

In the present study, the PV was seen to be formed at the lower border of popliteus in 28 specimens (93.33\%). Two specimens $(6.67 \%)$ showed a variable level of formation. The anterior and the posterior tibial veins united at the level of tibial condyle in one specimen as seen in [Table/Fig-2]. In one case, double anterior tibial vein was seen to be present [Table/Fig-3]. The proximally placed anterior tibial vein joined the posterior tibial vein at the level of tibial condyles and the distally placed anterior tibial vein joined the posterior tibial vein at the lower border of popliteus muscle.

\section{DISCUSSION}

In the embryo before $14 \mathrm{~mm}$ stage the axis artery of lower limb is the arteria ischiadica. At the level of knee joint the axis artery
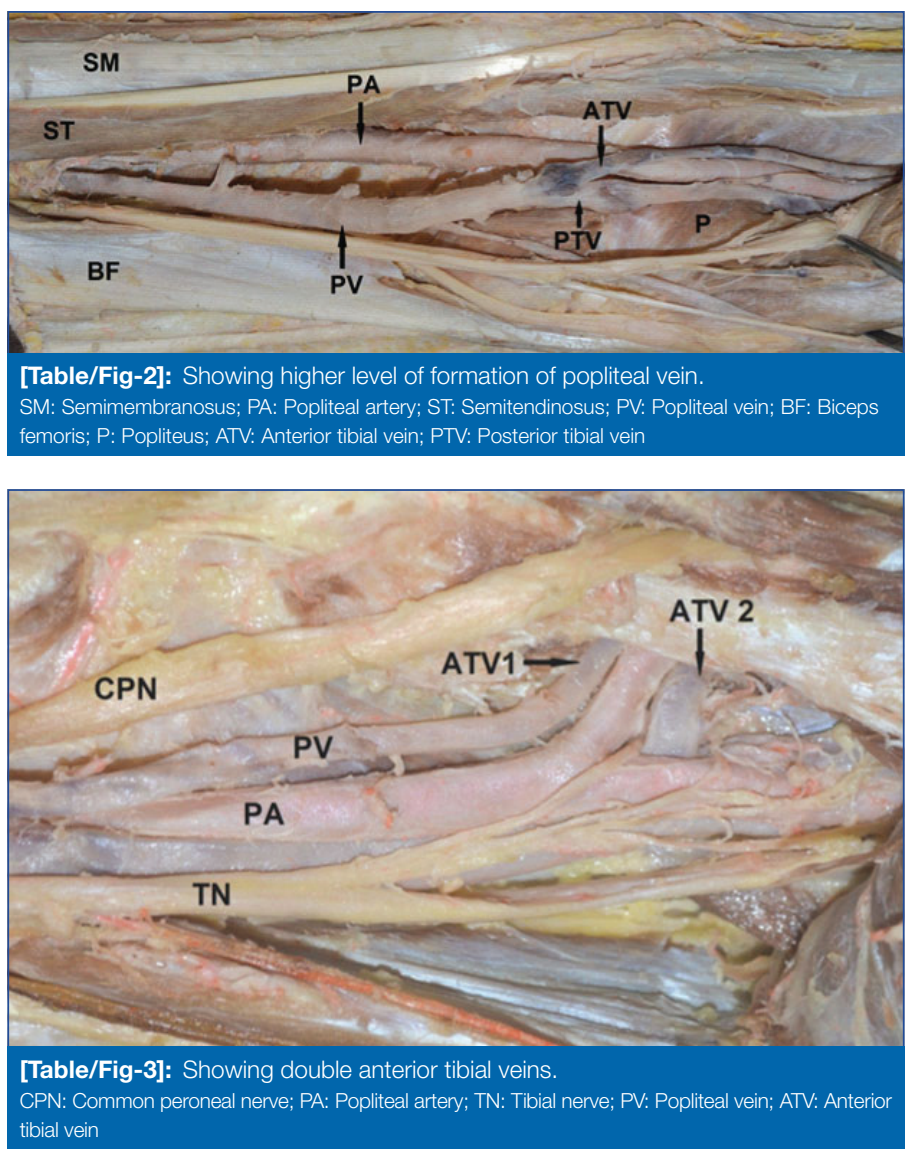

becomes popliteal. At $14 \mathrm{~mm}$ stage the arteria ischiadica is being supplemented by the femoral artery. The longitudinal arteries which traverse the leg in the embryo, the future posterior tibial and peroneal arteries, arise from the axial vessels at the upper border of popliteus muscle. A gradual proximodistal union of posterior tibial and peroneal artery occurs. This union forms the part of definite PA that lies behind popliteus muscle. A communicating branch from the lower border of popliteus enlarges to become definite anterior tibial artery [11].

Literature was reviewed to observe the variations in the PA branching pattern as studied by several authors and was compared to the findings of present study [Table/Fig-4]. Popliteal artery variations are not rare $[6,10]$. It has been reported to vary from $0.4-$ $12 \%$ [12-21]. The three most frequently encountered variations, following the usual patterns are: Type III A, Type II A and Type I B [20]. It is important to recognise anatomical variations for planning radiological and surgical intervention, particularly when rare Type III infra popliteal patterns are present. It may be necessary to modify the angioplasty technique to take in account absence of vessels to minimise complications [16]. In addition, harvesting of PA for free flap transfer procedure is contraindicated if Type III pattern is present. Because PA is the only artery that supplies the distal part of lower limb in Type IIIC branching pattern, this procedure could result in ischemia of foot [22].

Arteriographic studies have revealed that the most common vascular abnormality associated with clubfoot has been absent ATA, reported in $85 \%$ of children with clubfoot. Therefore, variations involving this vessel are of particular concern when these patients are managed surgically [18].

The present study was in concordance with studies done by Adachi B [13] and Trotter M [14] in having over 90\% Type IA branching pattern. In an analysis done by Tomaszewski KA et al, it was observed that Asian studies differed in type III analysis with a prevalence of $5.9 \%$ compared with prevalence rates of $2.0 \%$ and $3.3 \%$ in North Americans and Europeans, respectively. More specifically, Asians presented with a type III-B (hypoplasia or aplasia 


\begin{tabular}{|c|c|c|c|c|c|c|c|c|c|c|c|c|}
\hline Author & Type of study & $\begin{array}{l}\text { Number of } \\
\text { lower limbs }\end{array}$ & Type I A & Type I B & Type I C & $\begin{array}{c}\text { Type II } \\
\text { A1 }\end{array}$ & $\begin{array}{c}\text { Type II } \\
\text { A2 }\end{array}$ & $\begin{array}{l}\text { Type } \\
\text { II B }\end{array}$ & Type II C & Type III A & Type III B & Type III C \\
\hline Quain R [12] & Cadaveric & 258 & 90.3 & 6.6 & 2.3 & 0.8 & - & - & - & - & - & - \\
\hline Adachi B [13] & Cadaveric & 770 & 96 & 0.5 & 0.8 & 0.9 & 1 & 0.8 & - & - & - & - \\
\hline Trotter M [14] & Cadaveric & 1168 & 93.4 & 1.3 & 0.5 & 1.5 & 2.4 & 1.4 & - & - & - & - \\
\hline Keen JA [15] & Cadaveric & 280 & 90.7 & 0.4 & 4.3 & 3.6 & 0.4 & 1.1 & - & - & - & - \\
\hline $\begin{array}{l}\text { Day CP and } \\
\text { Orme R [16] }\end{array}$ & Angiogram & 1037 & 90 & 3.2 & 0.3 & 2.1 & - & 1.1 & 0.2 & 0.8 & 0.1 & 0.1 \\
\hline Mavili E [3] & DSA & 535 & 82.4 & 5.4 & 0.4 & 2.6 & - & 1.5 & - & 3.7 & 2.2 & 0.2 \\
\hline Ozgur Z [17] & Cadaveric & 40 & 90 & - & 2.5 & 5 & - & 2.5 & - & - & - & - \\
\hline Alsharawy S [18] & Cadaveric & 40 & 90 & 2.5 & - & - & - & - & - & 2.5 & - & - \\
\hline Oztekin PS [19] & CT Angiography & 495 & 87.5 & 3 & 1.2 & 1.4 & 0.4 & 1 & - & 3.3 & 0.6 & 0.4 \\
\hline Demirtas H [20] & CT Angiography & 1261 & 88.7 & 2.5 & 0.6 & 2.2 & 0.4 & 0.6 & - & - & 2.2 & 0.1 \\
\hline Kim D et al., [6] & Angiography & 605 & 92.6 & 1.2 & 2 & 3 & 0.7 & 0.8 & $<0.2$ & - & - & - \\
\hline Olewnik L [21] & Cadaveric & 80 & 72 & 12 & 8 & - & - & - & - & 8 & 1.2 & 0.1 \\
\hline Present Study & Cadaveric & 30 & 96.7 & & & 3.3 & & & & & & \\
\hline
\end{tabular}

of the AT) prevalence of $4.1 \%$ compared with $1 \%$ and $0.7 \%$ in North America and Europe, respectively. This reflects the findings in a previous study performed was only on the Japanese population, in which the only type III variation seen was of the type III-B variety. There was a lack of any other significant geographic differences or study modality (imaging or cadaveric) differences [23]. In the literature, gender-based comparisons are limited and no significant differences between the variation rates in females and males were reported in previous studies [24]. However, in a study conducted by Oner S and Oner Z, PA branching variations were about twice as frequent in females when compared to males (23\%, 11.9\%) [25]. Variations in lower limb venous anatomy are common and have important implications for diagnosis of conditions like deep vein thrombosis [26].

In a 9-week-old embryo, deep veins appear in form of and endothelialised vascular lacuna surrounding the arteries. The three networks- superficial primary postaxial, superficial secondary preaxial and deep ones- prefigure globally and respectively the short saphenous vein, the long saphenous vein and femoral vein and the deep popliteal and femoral veins. With time, anastomosis occurs between the superficial pre and postaxial and deep axial networks. The first anastomosis establishes a connection between the axial plexus below knee level with the preaxial plexus above knee level. This anastomosis generates the popliteal vein that drains all the deep leg axis to the thigh axial plexus [27].

Variations in anatomy of lower extremity venous system have been studied with use of cadavers venography and duplex ultrasound. These studies have shown different results depending on the study population and the modalities used [28].

The varied results of variation in formation of PV has been tabulated in [Table/Fig-5] [8,9,26,28-30].

\begin{tabular}{|c|c|c|c|c|}
\hline \multirow{2}{*}{$\begin{array}{l}\text { Author and } \\
\text { publication } \\
\text { Year }\end{array}$} & \multirow[b]{2}{*}{ Type of study } & \multirow[b]{2}{*}{$\begin{array}{l}\text { Number } \\
\text { of cases }\end{array}$} & \multicolumn{2}{|c|}{ Findings } \\
\hline & & & $\begin{array}{l}\text { High level } \\
\text { of formation }\end{array}$ & Duplication \\
\hline $\begin{array}{l}\text { Sadowska A et } \\
\text { al.,2013 [9] }\end{array}$ & Cadaveric & 64 & $18.17 \%$ & $7.8 \%$ \\
\hline $\begin{array}{l}\text { Quinlan DJ et } \\
\text { al.,2003 [26] }\end{array}$ & Venography & 808 & - & $5 \%$ \\
\hline \multirow{3}{*}{$\begin{array}{l}\text { Trigaux JP et } \\
\text { al.,1991 [29] }\end{array}$} & Cadavers & 12 & \multirow{3}{*}{-} & \multirow{3}{*}{$7 \%$} \\
\hline & CT scan & 40 & & \\
\hline & X-Ray & 30 & & \\
\hline $\begin{array}{l}\text { Simpson WL } \\
\text { and Krakowski } \\
\text { DM, } 2010 \text { [8] }\end{array}$ & $\begin{array}{l}\text { Duplex } \\
\text { ultrasound }\end{array}$ & 2664 & - & $10 \%$ \\
\hline
\end{tabular}

\begin{tabular}{|l|l|c|c|c|}
\hline $\begin{array}{l}\text { Park EH et al., } \\
2011 \text { [28] }\end{array}$ & $\begin{array}{l}\text { CT } \\
\text { venography }\end{array}$ & 1890 & $83 \%$ & $\begin{array}{c}2 \% \text { showed } \\
\text { multiplication } \\
\text { pattern } \\
10 \% \text { showed } \\
\text { complex networks }\end{array}$ \\
\hline $\begin{array}{l}\text { Dona E et al., } \\
2000 \text { [30] }\end{array}$ & $\begin{array}{l}\text { Duplex } \\
\text { ultrasound }\end{array}$ & 248 & - & $18 \%$ \\
\hline $\begin{array}{l}\text { Present study, } \\
2021\end{array}$ & Cadaveric & 30 & $6.67 \%$ & - \\
\hline
\end{tabular}

[Table/Fig-5]: Showing comparison of variations in the level of formation of popliteal vein $[8,9,26,28-30]$.

The present study is not in concordance with the above mentioned studies. There is a wide range of variation in level of formation of PV. There is as high incidence of a higher level of popliteal vein formation as 83\% [28] and as low as 18.1\% [9]. However, the incidence of duplication of popliteal vein has been reported to range between 2-18\% [23-25]. Veins serve as the best material for arterial grafting and therefore understanding deep and superficial veins is very important. Upto $73 \%$ of women and $53 \%$ men worldwide are diagnosed with Chronic Venous Insufficiency (CVI). The significance of lower limb venous anatomy was determined in line with the development of minimally invasive surgical interventions methods for CVI (laser, foam, subendothelial and thermal coagulation methods). The understanding of normal and variant anatomy is important to prevent complications during intervention [31].

\section{Limitation(s)}

The main limitation of present study was the small sample size. The work is based only on dissection; it's findings should be complimented by data from angiographic studies to make it clinically more significant. Also, since the number of male and female cadavers were not equal, comparison of the findings could not be done amongst both genders.

\section{CONCLUSION(S)}

Popliteal fossa is a region of interest to surgeons, radiologists and orthopaedic surgeons. Considering such variable morphology of popliteal vessels, a thorough knowledge of variant anatomy in this area is essential to plan procedures and avoid undue complications, therefore ensuring better patient outcome.

\section{REFERENCES}

[1] Mahadevan V. Knee. In: Standring S, Healy JC, Johnson D, Collins P, Borley $\mathrm{NR}$, Crossman AR, et al. editors. Gray's Anatomy, 40 th ed. China: Churchill Livingstone; 2008:1393-410.

[2] Tindal AJ, Shetty AA, James KD, Middleton A, Fernando KWK. Prevalence and surgical significance of high- Origin anterior tibial artery. J Orthop Surg (Hong Kong). 2006;14:13-16. 
[3] Mavili E, Donmez H, Kahriman G, Ozaslamaci A, Ozcan N, Tasdemir K. Popliteal artery branching patterns detected by digital subtraction angiography. Diagn Interv Radiol. 2011; 17:80-83.

[4] The Popliteal Fossa. In: Roman GJ editor. Cunningham's Manual of Practical Anatomy, $15^{\text {th }}$ ed. United States of America: Oxford Medical Publication; 1986: 160-65.

[5] Vascular Approach. In: Decker GAG, Plessis DJ, editors. Lee McGregor's Synopsis of Surgical Anatomy. $12^{\text {th }}$ ed. Bombay: Varghese Publishing house; 1986:239-48.

[6] Kim D, Orron DE, Skillman JJ. Surgical significance of popliteal arterial variants. A unified angiographic classification. Ann Surg. 1989;210:776-81.

[7] Colborn GL, Lumsden AB, Taylor BS, Skandalakis JS. The surgical anatomy of popliteal artery. Am Surg. 1994;60:238-46.

[8] Simpson WL, Krakowsi DM. Prevalence of lower extremity venous duplication. Indian J Radiol Imaging. 2010; 20:230-34.

[9] Sadowska A, Spodnik JH, Wojcik S. Variations in popliteal fossa venous anatomy: Implications for diagnosis of deep vein thrombosis. Folia Morphol. 2013;72:51-56.

[10] Kil SW, Jung GS. Anatomical variations of the popliteal artery and its tibia branches: Analysis in 1242 extremities. Cardiovasc Intervent Radiol. 2009;32:233-40

[11] Singla R, Kaushal S, Chabbra U. Popliteal artery branching pattern: A cadaveric study. Eur J Anat. 2013;16(2):157-62.

[12] Quain R. Anatomy of the arteries of human body. London: Taylon \& Walton; 1844:415-22.

[13] Adachi B. Das Arteriensystem der Japaner, vol 2. Verlag der Kais Univ zu Koyoto;1982:18-71.

[14] Trotter M. The level of termination of popliteal artery in the White and the Negro. Am J Phys Anthropol. 1940;27:109-18.

[15] Keen JA. A study of the arterial variations in the limbs, with special reference to symmetry of vascular patterns. Am J Anat. 1961;108:245-61.

[16] Day CP, Orme R. Popliteal artery branching patterns- An angiographic study. Clin Radiol. 2006;61:696-99.

[17] Ozgur Z, Ucerler H, Aktan Ikiz ZA. Branching pattern of the popliteal artery and its clinical importance. Surg Radiol Anat. 2009;31:357-62.

[18] Alsharawy S, Atteya M, Muhammad R, Aldahmash A, Alfeyez M, Elessawy M, et al. Variations in popliteal artery branching patterns. IJIB. 2012;13(1):04-08.
[19] Oztekin PS, Ergun E, Civgin E, Yigit H, Kosar PN. Variants of the popliteal artery terminal branches as detected by multidetector ct angiography. Open Med Warsaw, Poland). 2015;10:483-91.

[20] Demirtas H, Degirmenci B, Celik AO, Umul A, Kara M, Aktas AR, et al. Anatomic variations of popliteal artery: Evaluation with 128-section CT-angiography in 1261 lower limbs. Diagn Interv. 2016;(97):635-42

[21] Olewnik L, Labetowicz P, Podgorski M, Polguj M, Ruzik K, Topol M. Variations in terminal branches of the popliteal artery: Cadaveric study. Surg Radiol Anat. 2019;41:1473-82

[22] Yanik B, Bulbul E, Demirpolat G. Variations of the popliteal artery branching with multidetector CT angiography. Surg Radiol Anat. 2015:37:223-30.

[23] Tomaszewski KA, Popieluszko P, Graves MJ, Pẹkala PA, Henry BM, Roy J, et al. The evidence based surgical anatomy of the popliteal artery and the variations in its branching patterns. J Vasc Surg. 2017;65:521-29.

[24] Celtikci P, Ergun O, Durmaz HA, Conkbayir I, Hekimoglu B, Evaluation of popliteal artery branching patterns and a new subclassifcation of the 'usual' branching pattern. Surg Radiol Anat. 2017;39:1005-15

[25] Oner S, Oner Z. Popliteal artery branching variations: A study on multidetector CT angiography. Scientific Reports. 2020;10:8147.

[26] Quinlan DJ, Alikhan R, Gishen P, Sidhu PS. Variations in lower limb venous anatomy: Implications for US diagnosis of deep vein thrombosis. Radiology. 2003:228:443-48

[27] Creton D. Saphenopopliteal junctions are significantly lower when incompetent. Embryological hypothesis and surgical implications. Phlebolymphology. 2005;48:347-54.

[28] Park EH, Chung JW, Lee W, Yin YH, Ha J, Kim SJ, et al. Three-dimensiona evaluation of anatomic variations of the femoral vein and popliteal vein in relation to the accompanying artery by using CT venography. Korean J Radiol. 2011;12:327-40.

[29] Trigaux JP, Beers BV, Wispelaere JFD. Anatomic relationship between the popliteal artery and vein: A guide to accurate angiographic puncture. AJR. 1991;157:1259-62.

[30] Dona E, Fletcher JP, Hughes TM, Saker K, Batiste P, Ramanathan I. Duplicated popliteal and superficial femoral veins: Incidence and potential significance. Aust N Z J Surg. 2000;70:438-40.

[31] Krievins D, Zarina RR, Savlovskis J, Dombure P. Variations in lower limb deep venous anatomy in Latvia. Acta Chirurgica Latviensis. 2013;13:51-56.

\section{PARTICULARS OF CONTRIBUTORS:}

1. Assistant Professor, Department of Anatomy, Christian Medical College, Ludhiana, Punjab, India.

2. Professor, Department of Anatomy, Christian Medical College, Ludhiana, Punjab, India.

3. Honorary Adjunct Lecturer, Department of Anatomy, Adelaide Medical School, Adelaide, Australia.

\section{NAME, ADDRESS, E-MAIL ID OF THE CORRESPONDING AUTHOR:}

Dr. Angel,

Assistant Professor, Department of Anatomy, Christian Medical College,

Ludhiana, Punjab, India.

E-mail: drangelanatomy@gmail.com
PLAGIARISM CHECKING METHODS: ${ }^{[\mathrm{ain} H \mathrm{H} \text { et al.] }}$

- Plagiarism X-checker: Oct 01, 2020

- Manual Googling: Nov 10, 2020

- iThenticate Software: Mar 06, 2021 (25\%)

\section{AUTHOR DECLARATION:}

- Financial or Other Competing Interests: None

- Was Ethics Committee Approval obtained for this study? Yes

- Was informed consent obtained from the subjects involved in the study? No

- For any images presented appropriate consent has been obtained from the subjects. No

Date of Submission: Oct 01, 2020 Date of Peer Review: Oct 27, 2020 Date of Acceptance: Dec 19, 2020 Date of Publishing: Apr 01, 2021 